\title{
Mindfulness and Marital Satisfaction
}

\section{Citation}

Burpee, Leslie C., and Ellen J. Langer. 2005. Mindfulness and marital satisfaction. Journal of Adult Development 12, no. 1: 43-51.

\section{Published Version}

http://dx.doi.org/10.1007/s10804-005-1281-6

\section{Permanent link}

http://nrs.harvard.edu/urn-3:HUL.InstRepos:3160495

\section{Terms of Use}

This article was downloaded from Harvard University's DASH repository, and is made available under the terms and conditions applicable to Other Posted Material, as set forth at http:// nrs.harvard.edu/urn-3:HUL.InstRepos:dash.current.terms-of-use\#LAA

\section{Share Your Story}

The Harvard community has made this article openly available.

Please share how this access benefits you. Submit a story.

Accessibility 


\title{
Mindfulness and Marital Satisfaction
}

\author{
Leslie C. Burpee $^{1}$ and Ellen J. Langer ${ }^{1,2}$
}

\begin{abstract}
This study investigated the relationships among mindfulness, marital satisfaction, and perceived spousal similarity. All 95 subjects responded to a questionnaire measuring each of these variables, and an additional series of demographic variables. A significant positive relationship was found between mindfulness and marital satisfaction, with no statistically significant relationship found between perceived spousal similarity and marital satisfaction. There was a stronger correlation between mindfulness and marital satisfaction than the correlation between marital satisfaction and any of the other variables, including similarity. These results carry meaningful implications for the role of mindfulness techniques within the context of building and maintaining happy marital relationships and general well-being.
\end{abstract}

KEY WORDS: mindfulness; marital satisfaction.

\section{INTRODUCTION}

Mindfulness is the process of actively drawing novel distinctions. It results in context-sensitivity and a heightened awareness of alternative perspectives (Langer, 1989). In contrast, mindlessness is based in the past. It occurs when an individual gets locked into patterns of behavior either over time or on initial exposure. It results in insensitivity to context and perspective.

The current research applies the concept of mindfulness to close relationships, specifically marriage, by measuring its relationship to marital satisfaction. It is hypothesized that spouses who score higher in mindfulness also will score high in marital satisfaction. Mindful techniques, such as drawing distinctions across situations, acknowledging the existence of alternative perspectives, and recognizing that disadvantages may also be advantages from others' points of view, may help foster more positive and satisfying marital relationships by creating an environment that is rich with open-mindedness and flexibility, rather than criticism and rigidity.

\footnotetext{
${ }^{1}$ Department of Psychology, Harvard University, Cambridge, Massachusetts.

${ }^{2}$ To whom correspondence should be addressed at Department of Psychology, Harvard University, 33 Kirkland Street, Cambridge, Massachusetts 02138; e-mail: langer@wjh.harvard.edu.
}

The current study seeks to measure the relationship between marital satisfaction and mindfulness. Marital satisfaction is measured as the degree to which spouses perceive that their partners meet their needs and desires (Bahr, Chappell, \& Leigh, 1983; Bohlander, 1999; Fields, 1983).

Different factors may contribute to the happiness of some marriages more than others. The purpose of the current research is not to decipher which factors prevail as most influential, but to suggest that a tendency towards mindfulness may be positively correlated with an individual's sense of overall marital satisfaction. One of the most pervasive and heavily investigated marital satisfaction theories is that individuals seek out and marry other individuals who share more similarities than differences in personality, interests, and behavioral tendencies (Bruch \& Skovholt, 1985; Lewak \& Wakefield, \& Briggs, 1985; Sherman \& Jones, 1994). The idea is that marital satisfaction is enhanced by such selection because when couples have little in common, the probability for conflict and marital demise is relatively high (Bruch \& Skovholt, 1985). If one spouse scores high in extraversion and the other scores low, they are likely to have a low level of marital satisfaction (Buss, 1991).

Numerous studies suggest a relationship between spousal personality similarity and marital 
satisfaction (Blum \& Mehrabian, 1999; Bouchard, Lussier, \& Sabourin, 1999; Bruch \& Skovholt, 1985; Holden, 1991; Kelly \& Conley, 1987; Kim, Martin, \& Martin, 1989; Nemechek \& Olson, 1999; Richard, Wakefield, \& Lewak, 1990). It is thought, for example, that couples that share more similarities than differences might engage in fewer arguments, have fewer misunderstandings, and less overall conflict or negative interaction, than other couples (Caspi \& Herbener, 1990).

Some researchers reason that individuals choose similar partners because congruent traits and behaviors make a person feel validated, and comfortable with their self-image, and therefore, more aligned with their spouses (Nemechek \& Olson, 1999). Nemechek and Olson suggest that similarity may be more appealing because there is some inherent byproduct of similarity that elicits a more satisfying relationship. That is, perhaps similar spouses are more prone to understand one another's perspective, so fewer misunderstandings ensue.

The alternative to the above concept of selection of similar partners is that individuals choose partners with complementary personalities and attitudinal traits in order to achieve a greater sense of wholeness (Winch, Ktsanes, \& Ktsanes, 1954). There is little support for this idea that happy marriages result from opposites attracting, but enough evidence exists to keep researchers from discarding it entirely (Lewak et al., 1985; Sherman \& Jones, 1994). In addition, although most studies point to the ill effects of complementary personalities in married dyads, some researchers offer the side-note that having a few, rather than all, complementary traits could be healthy, and in fact, this is often the case in happy couples (Sherman \& Jones, 1994).

Given the obvious disparity between these two approaches, similarity versus complementarity, many researchers have sought reconciliation by identifying just one personality type that correlates with marital satisfaction rather than an all-or-none premise. For example, and not surprisingly, there is nearly unanimous agreement that a strong negative relationship between neuroticism and marital dissatisfaction exists (Buss, 1991; Hjemboe \& Butcher, 1991; Kelly \& Conley, 1987; Kosek, 1996; Lester, Haig, \& Monello, 1989). That is, a couple in which one member shows evidence of anxiety, depression, (Bouchard, et al., 1999; Kosek, 1996) emotional instability, poor impulse control, feelings of social inferiority (Buss, 1991; Hjemboe \& Butcher, 1991; Kelly \& Conley, 1987), and/or hypersensitivity to criticism (Lester, et al., 1989; Nemechek \& Olson, 1999) may experience higher rates of conflict and lower levels of marital satisfaction.

Though personality traits and behavioral tendencies are not mutually exclusive, researchers have found that each can bring different dynamics to a relationship (Johnson \& Booth, 1998). Further, since personality traits have been found to be relatively static and unchangeable over time (Johnson \& Booth, 1998), focusing one's attention on changing or reevaluating a behavior may yield better and more immediate results than attempting to change an aspect of one's personality.

Gottman (1994) and his team of researchers at the University of Washington have studied this approach to understanding marital satisfaction over many years, and have proposed that the ratio of positive to negative interactions tells a great deal about the relative success of a marriage. That is, if a couple interacts five times in a positive manner for every one negative exchange, the marriage is likely to be high in marital satisfaction (Gottman, 1994).

Conflict is not unusual in the context of a marriage, and may even deliver long-term benefits, if handled in a particular manner (Gottman \& Krokoff, 1989). When characterized by stubbornness, defensiveness, and withdrawal, conflicts become detrimental to the relationship because these elements remove the possibility for cooperation and constructive interaction (Gill, Christensen, \& Fincham, 1999; MacEwen \& Barling, 1993; Pasupathi, Carstensen, Levenson, \& Gottman, 1999; Zimmerman \& Dickerson, 1993). When couples handle conflict together with the mutual intent to repair emotional damage, however, each spouse is likely to leave the conflict feeling better (Mackey, Diemer, \& O'Brien, 2000). Discussing difficult issues is likely to reveal each partner's perspective and result in a greater mindfulness on both parts.

Many researchers who find a high correlation between behavioral congruence, rather than personality congruence, and marital satisfaction recommend that couples find a combination of behaviors that are most conducive to positive conflictmanagement, that is, behaviors that enable spouses to solve problems with mutual respect and empathy (Gill et al., 1999; Gottman \& Krokoff, 1989). Just as personality theorists claim with great substantiation that neuroticism taints the quality of any marriage, behavior theorists are quick to categorize such conduct as avoidance, defensiveness, and stubbornness as dysfunctional for a healthy marriage. 
A couple's beliefs that their personalities are in congruence is a better indicator of marital satisfaction than their actual similarities in personality or behavior (Kaslow \& Robinson, 1996; Merves-Okin, Amidon, \& Bernt, 1991; Plechaty, 1987). The degree to which their beliefs about the marriage and each other are aligned is likely to have major importance. Research has in fact indicated that satisfied couples tend to demonstrate greater perceptual congruence than dissatisfied couples (Buunk \& Mutsaers, 1999; Plechaty, 1987).

Perceptual congruence may be the result of mindfulness. That is, the degree to which a spouse can willingly consider reevaluating his or her perception of his or her partner in a given situation might allow for greater flexibility and resiliency across situations. The concept of mindfulness (Langer, 1989, 1997, 2002) can be described as the practice of three basic principles: drawing novel distinctions and questioning automatic behavior, defying the limits of categories and premature cognitive commitments, and considering alternative perspectives. Over time, mindlessness is likely to increase. These automatic responses discourage one from actively taking part in the choices at hand; the presence of more than one option remains unacknowledged, and the unique circumstances of the present situation go unnoticed. This tendency is particularly salient to relationships in which spouses have developed mindless responses to recurring conflicts or daily rituals that may have once held great meaning, but the occurrences of which have now become ordinary and unremarkable. The more similar partners are, the less likely it is that they will see the issue in question from different perspectives, thus, when mindful, similarities should result in fewer marital conflicts.

Each individual builds his or her perspective based on past experiences and present conditions. In all ways we are different from our partners, we may be oblivious to the way the partner's perspective may differ from our own. By mindfully considering how others may interpret the same information differently, the possibility emerges for more solutions to mundane problems. We may recognize that even some perceived disadvantages could be advantages when considered from another individual's point of view. Behavior makes sense from the actor's perspective or else the actor would behave differently. Therefore, alternative views may both be sensible.

Several studies suggest that couples with high marital satisfaction are more likely to rate high in open-mindedness (Buss, 1991; Kim et al., 1989; Nemechek \& Olson, 1996), which is clearly related to mindfulness.

\section{METHOD}

\section{Subjects/Procedure}

We offered participants a confidential opportunity to be in a study on relationships. Subjects entered all responses to the questionnaire online, and such responses were sent via e-mail to the researcher. Sixty percent of the total data were collected using this method. The remaining participants were recruited by personal contacts and via regular mail. Subjects ranged in age from 25 to 74, and included 55 women and 40 men, all of whom were currently married.

The researchers ascertained demographic information, including age, gender, number of years married, and whether they had been married prior to their current marriage (since participants with more marriage experience might have more information about their spouses and/or more knowledge of issues about marriage in general), and other variables that might be relevant, such as education level, number of children, number and age of siblings, and number of pets.

Next, subjects completed a brief questionnaire with 14 questions regarding overall life satisfaction, including five marital satisfaction questions and one question addressing the degree of perceived overall similarity between the subject and his or her spouse. Only these six questions were considered and counted in the data analysis, the rest were included only to limit demand characteristics by deemphasizing marital satisfaction as a primary variable in the minds of participants. Subjects' answers to the five questions addressing marital satisfaction were totaled, and this number represented their overall marital satisfaction score. Subjects' responses to the sixth question that covers perceived spousal similarity served as the similarity score. An 11-point scale, ranging from 0 to 10 followed all questions, and subjects were asked to circle the number that best described their response. Subjects' ratings of overall spousal similarity and mindfulness scores were compared with marital satisfaction scores in order to determine whether relationships exist among the three variables. 
Finally, participants completed the mindfulness scale. This scale measures four key dimensions of mindfulness: novelty seeking, novelty producing, flexibility, and engagement (Langer, 2001).

Completing all three portions of the questionnaire signaled the completion of subjects' participation. All subjects were then given a debriefing letter outlining the purpose and procedure of the study.

\section{RESULTS}

A regression analysis concluded with $>95 \%$ certainty that a non-zero correlation exists between mindfulness and marital satisfaction with a high degree of statistical significance $\left(r=.277, r^{2}=.077, t=\right.$ $2.78, p<.01)$. Therefore, the null hypothesis that no relationship exists between mindfulness and marital satisfaction must be rejected and it is concluded with a high probability $(1-0.0065=0.9935)$ that a relationship does exist (Table I, Fig. 1).

\section{Magnitude and Sign of the Relationship}

Participants' scores on mindfulness, marital satisfaction, and similarity were normalized to range from 0 to 100 . The data show a mean normalized marital satisfaction score of 80.16 (Standard Deviation 6.62) and a mean normalized mindfulness score of 69.76 (Standard Deviation 8.28). All scores were analyzed using regression analysis, with marital satisfaction as the dependent variable and mindfulness as the independent variable.

As shown in Table I, the correlation coefficient is positive and relatively high $(r=.28)$. The $95 \%$ confidence interval for the coefficient $r=.28$ is $(.13, .76)$. The regression coefficient was .44 with a standard error of .16 , meaning that a 2.76 standard deviation error on the low side would be required before the coefficient would be decreased to zero. The predictive equation that describes the relationship between the two variables is as follows: marital satisfaction $=0.44 x+49.26$. Nearly $8 \%$ of the variability in marital satisfaction was explained by mindfulness $\left(r^{2}=\right.$ .077). Considering the vast number of additional factors that may contribute to marital satisfaction, $8 \%$ is a substantial portion to be attributed to a single factor. The relationship between similarity and marital satisfaction was unsubstantial and insignificant (Table II, Fig. 2).

To evaluate whether a multi-dimensional relationship exists among mindfulness, similarity, and marital satisfaction, a multiple regression analysis was performed. The coefficient on the combined relationship did not differ from the correlation coefficient for mindfulness $\left(r=.28, r^{2}=.08\right)$. The $t$ value for the correlation coefficient on similarity was not significant, leading to the conclusion that adding the similarity factor did not meaningfully change the relationship to marital satisfaction. In contrast, the $t$ value for mindfulness within this multiple regression is highly significant $(t=2.61, p<.05)$. In conclusion, even when coupled with mindfulness, the amount of marital satisfaction scores that is explained by similarity in this research is small (Table III).

Table I. Mindfulness and Marital Satisfaction Regression

\begin{tabular}{|c|c|c|c|c|c|c|}
\hline $\begin{array}{l}\text { Regression analysis } \\
.077 r^{2} \\
.277 r \\
12.786 \text { Std. error of estimate } \\
95 \text { Observations } \\
1 \text { Predictor variable } \\
\text { Marital satisfaction score } \\
\text { Confidence interval }\end{array}$ & Dependent variable & & & & & \\
\hline Variables & Coefficients & Std. error & $t(d f=93)$ & $p$-Value & $95 \%$ lower & $95 \%$ upper \\
\hline $\begin{array}{l}\text { Intercept } \\
\text { Mindfulness score }\end{array}$ & $\begin{array}{l}a=49.2578 \\
b=0.443125\end{array}$ & 0.159209 & 2.78 & .0065 & 0.126968 & 0.759283 \\
\hline ANOVA table & & & & & & \\
\hline Source & SS & $d f$ & MS & $F$ & $p$-Value & \\
\hline $\begin{array}{l}\text { Regression } \\
\text { Residual } \\
\text { Total }\end{array}$ & $\begin{array}{r}1,266.3716 \\
15,202.9337 \\
16,469.3053\end{array}$ & $\begin{array}{r}1 \\
93 \\
94\end{array}$ & $\begin{array}{r}1,266.3716 \\
163.4724\end{array}$ & 7.75 & .0065 & \\
\hline
\end{tabular}




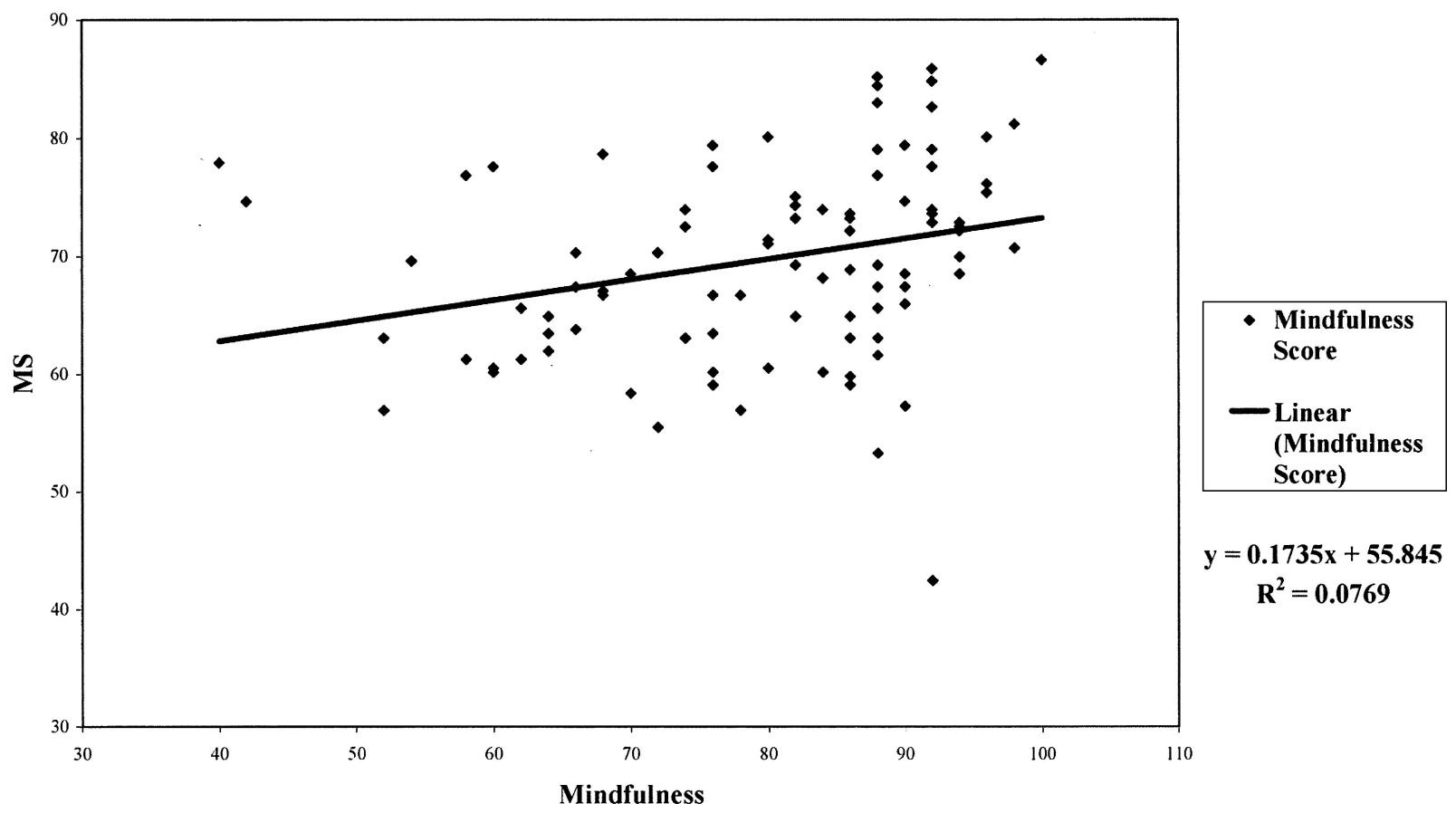

Fig. 1. Relationship of mindfulness to marital satisfaction.

\section{Mindfulness Dimensions}

Questions on the mindfulness scale covered four dimensions, each of which was analyzed separately in order to determine whether certain dimensions held stronger correlations to marital satisfaction than others. The novelty producing $(M=48.15, S D=8.50$; $\left.r=.26, r^{2}=.07, p<.05\right)$, novelty seeking $(M=$ 57.51, $\left.S D=7.83 ; r=.22, r^{2}=.09, p<.01\right)$ shared statistically significant and positive correlations with marital satisfaction. The flexibility scores did not produce a statistically significant result.

\section{Demographic Variables}

Demographic variables were also assessed in order to determine whether meaningful relationships might exist among such variables and the three

Table II. Similarity and Marital Satisfaction Regression Analysis

Regression analysis

$.009 r^{2}$

$.094 r$

13.249 Std. error of estimate

95 Observations

1 Predictor variable

Marital satisfaction score Dependent variable

Confidence interval

\begin{tabular}{lcccccc}
$\quad$ Variables & Coefficients & Std. error & $t(d f=93)$ & $p$-Value & $95 \%$ lower & $95 \%$ upper \\
\hline $\begin{array}{l}\text { Intercept } \\
\text { Similarity score }\end{array}$ & $\begin{array}{l}a=76.0010 \\
b=0.0599\end{array}$ & 0.0661 & 0.91 & .3672 & -0.0714 & 0.1911 \\
$\begin{array}{l}\text { ANOVA table } \\
\quad \text { Source }\end{array}$ & SS & $d f$ & MS & $F$ & $p$-Value \\
\multicolumn{1}{r}{ Regression } & 144.1495 & 1 & 144.1495 & 0.82 & .3672 \\
Residual & $16,325.1558$ & 93 & 175.5393 & & \\
Total & $16,469.3053$ & 94 & & & \\
\hline
\end{tabular}




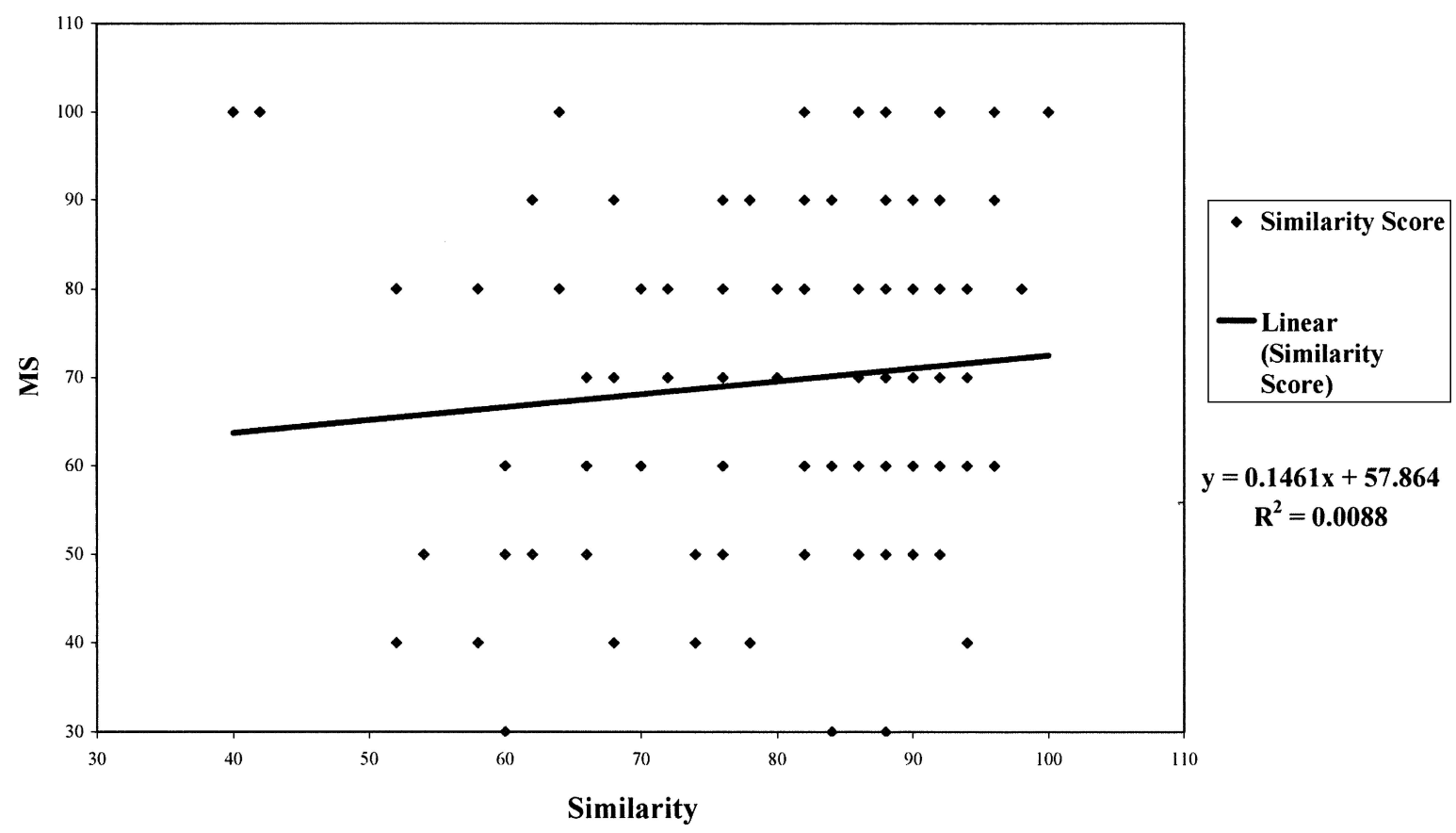

Fig. 2. The relationship between marital satisfaction and spouse similarity.

primary dimensions, marital satisfaction, mindfulness, and similarity. As shown in Table IV, none of the correlation coefficients with marital satisfaction were as high as those for mindfulness.

All demographic variables were assessed together in a multiple regression analysis; when combined, they accounted for roughly $20 \%$ of marital satisfaction $\left(R=.45, R^{2}=.198, p<.05\right)($ Table V).
Demographics were also analyzed individually in order to determine whether certain social or age groups demonstrated distinct patterns in their average marital satisfaction, mindfulness, and similarity scores. Data within each demographic category were divided into the top range and bottom range of the data. In order to test whether these two subgroups scored in significantly different ways, $t$ tests were applied.

Table III. Mindfulness, Similarity, and Marital Satisfaction Multiple Regression Analysis

\begin{tabular}{|c|c|c|c|c|c|c|c|}
\hline $\begin{array}{l}\text { Regression analysis } \\
0.077 R^{2} \\
0.277 R \\
12.855 \text { Std. error of estimate } \\
95 \text { Observations } \\
2 \text { Predictor variables } \\
\text { Marital satisfaction score } \\
\text { Confidence interval }\end{array}$ & Dependent variable & & & & & & \\
\hline Variables & Coefficients & Std. error & $t(d f=92)$ & $p$-Value & $91 \%$ lower & $95 \%$ upper & $\beta$ \\
\hline $\begin{array}{l}\text { Intercept } \\
\text { Mindfulness score } \\
\text { Similarity score } \\
\text { ANOVA table }\end{array}$ & $\begin{array}{l}b 0=49.2205 \\
b 1=0.440860 \\
b 2=0.0028\end{array}$ & $\begin{array}{l}0.169150 \\
0.0678\end{array}$ & $\begin{array}{l}2.61 \\
0.04\end{array}$ & $\begin{array}{l}.0107 \\
.9670\end{array}$ & $\begin{array}{l}0.104913 \\
-0.1318\end{array}$ & $\begin{array}{l}0.776807 \\
0.1374\end{array}$ & $\begin{array}{l}0.276 \\
0.004\end{array}$ \\
\hline Source & SS & $d f$ & MS & $F$ & $p$-Value & & \\
\hline $\begin{array}{l}\text { Regression } \\
\text { Residual } \\
\text { Total }\end{array}$ & $\begin{array}{r}1,266.6552 \\
15,202.6501 \\
16,469.3053\end{array}$ & $\begin{array}{r}2 \\
92 \\
94\end{array}$ & $\begin{array}{l}633.3276 \\
165.2462\end{array}$ & 3.83 & .0252 & & \\
\hline
\end{tabular}


Table IV. Correlation Matrix for All Variables

\begin{tabular}{|c|c|c|c|c|c|c|c|c|c|c|}
\hline & $\begin{array}{c}\text { Marital } \\
\text { satisfaction } \\
\text { score }\end{array}$ & $\begin{array}{l}\text { Mind- } \\
\text { fulness } \\
\text { score }\end{array}$ & $\begin{array}{c}\text { Similarity } \\
\text { score }\end{array}$ & Age & $\begin{array}{c}\text { Years } \\
\text { of } \\
\text { marriage }\end{array}$ & $\begin{array}{c}\text { Total } \\
\text { number } \\
\text { of children }\end{array}$ & $\begin{array}{c}\text { Number } \\
\text { of } \\
\text { pets }\end{array}$ & $\begin{array}{c}\text { Total } \\
\text { number } \\
\text { of siblings }\end{array}$ & $\begin{array}{c}\text { Older } \\
\text { siblings }\end{array}$ & $\begin{array}{c}\text { Education } \\
\text { level }\end{array}$ \\
\hline Marital satisfaction score & 1.000 & & & & & & & & & \\
\hline Mindfulness score & .277 & 1.000 & & & & & & & & \\
\hline Similarity score & .094 & .323 & 1.000 & & & & & & & \\
\hline Age & -.013 & .053 & .188 & 1.000 & & & & & & \\
\hline Years of marriage & -.135 & -.047 & .114 & .918 & 1.000 & & & & & \\
\hline Total number of children & -.232 & .134 & .115 & .569 & .564 & 1.000 & & & & \\
\hline Number of pets & .024 & .028 & .082 & .153 & .155 & .137 & 1.000 & & & \\
\hline Total number of siblings & -.121 & .012 & -.069 & -.111 & -.070 & .147 & .050 & 1.000 & & \\
\hline Older siblings & -.208 & -.038 & -.071 & .046 & .058 & .198 & .028 & .629 & 1.000 & \\
\hline \multirow[t]{2}{*}{ Education level } & .201 & .315 & .073 & -.084 & -.195 & -.067 & .095 & .073 & .111 & 1.000 \\
\hline & & & & $\begin{array}{l} \\
\pm .202 \mathrm{c} \\
\pm .263 \mathrm{c}\end{array}$ & $\begin{array}{l}95 \text { sample } \\
\text { ritical value } \\
\text { ritical value }\end{array}$ & $\begin{array}{l}\text { size } \\
.05 \text { (two-tail } \\
.01 \text { (two-tail }\end{array}$ & & & & \\
\hline
\end{tabular}

Results were divided into upper and lower sections, multiple regression analyses were run in order to determine whether mindfulness scores held more significant relationships to marital satisfaction for one group than another. Mindfulness was found to be a particularly important marital satisfaction factor for certain demographic subgroups: those 40 or more years old, those married nine or more years, those not previously married, those with chil- dren, those with pets, those with zero to one sibling, and those with no older siblings.

\section{DISCUSSION}

The present research indicates that there is a strong relationship between mindfulness and marital satisfaction. As expected, no single variable,

Table V. Demographic Variables and Marital Satisfaction Multiple Regression Analysis

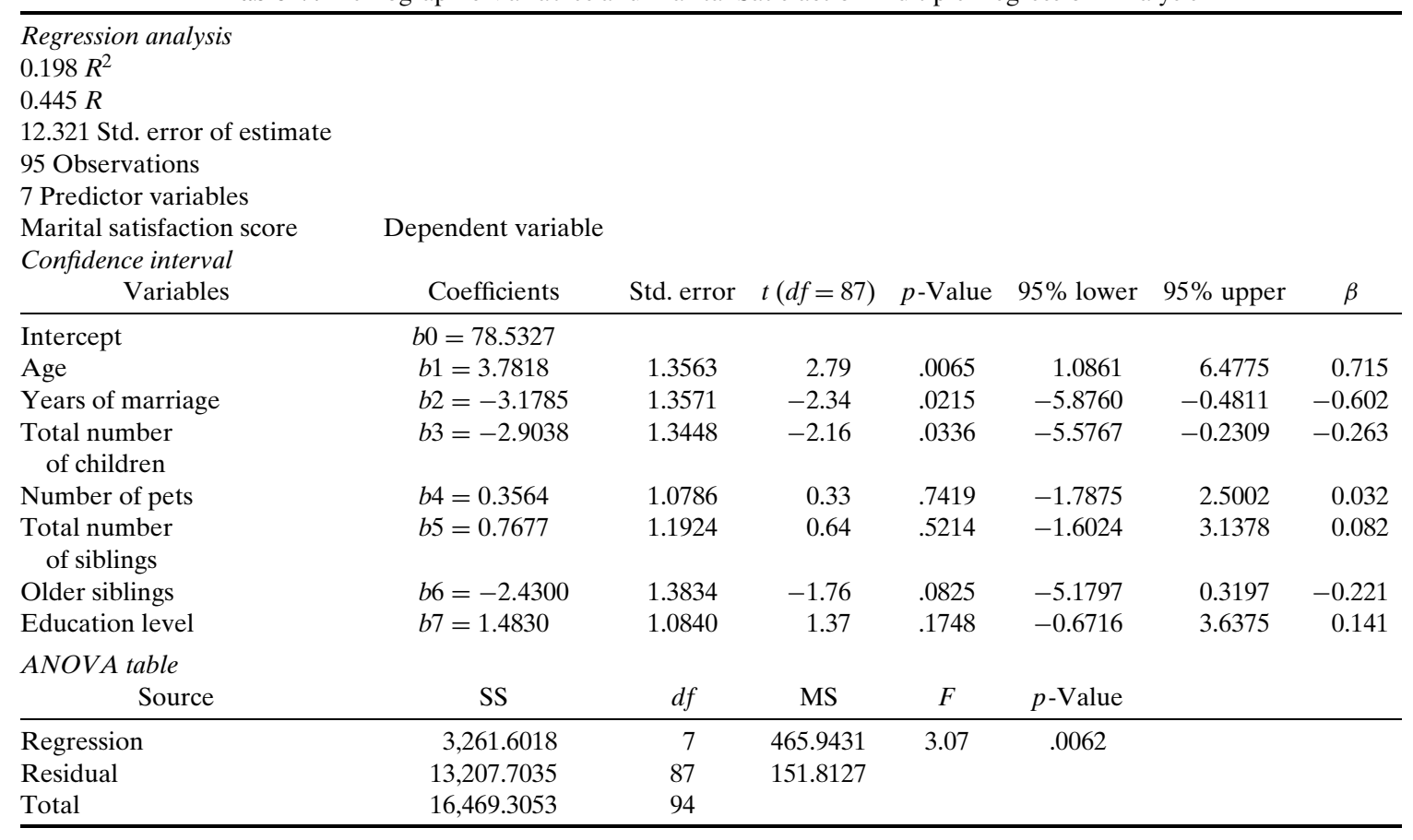


including any of the demographic factors or the similarity score, was as important for marital satisfaction as mindfulness, which accounted for roughly $8 \%$ of overall marital satisfaction. This suggests that spouses who are mentally engaged, open to new experiences, and aware of new contexts enjoy more satisfying and fulfilling marital relationships.

Mindful individuals may feel less threatened by change. When relationships are held constant and ignore changing contexts, the possibility for conflict and unhappiness is likely to increase. It is often assumed that a relationship stays stable when a person "gets to know" their spouse. But once an opinion is formed, there is a danger that little opportunity is left for reevaluating, rediscovering that same individual in a new situation or context. In contrast, in a mindful state beliefs and attitudes about an individual and the relationship are more malleable and ever-changing (Langer, 1989).

When conflict arises, many couples develop patterns of negative reactions that only intensify the original conflict. The emphasis often shifts from finding a mutual solution to assigning blame. A mindful individual is less likely to make mindless attributions, and more likely to consider the existence of his or her spouse's point of view.

\section{Comparison with Similarity}

It is interesting that there was no relationship found among marital satisfaction and perceived personality and behavior similarity. Spousal similarity is one of the most highly researched marital satisfaction factors (Blum \& Mehrabian, 1999; Bouchard et al., 1999; Bruch \& Skovholt, 1985; Holden, 1991; Kelly \& Conley, 1987; Kim et al., 1989; Nemechek \& Olson, 1999; Richard et al., 1990), yet even when combined with mindfulness in a multiple regression, similarity accounted for relatively low marital satisfaction variability. Mindfullness explained almost exactly the same amount when combined with similarity as alone, approximately $8 \%$. Once we understand another person's behavior from that person's perspective, we are likely to see ourselves as similar; if we saw it the way they did, we would have acted as they did. The more mindful we are, the less evaluative we become. The existence of differences in personality and behavior alone might not be as related to marital satisfaction as an individual's mindless unwillingness to accept or appreciate such differences, or one's assumption that another person's unique qualities are less favorable than one's own.

\section{Demographic Variables}

As the demographic results of this study suggest, younger individuals are generally more happily married than older individuals, especially if they have been married for a shorter, rather than longer, period of time. It appears that as time passes, relationships may experience less overall satisfaction, perhaps because couples have more difficulty defending the accumulation of mindless daily rituals, or keeping their marriages fresh and interesting. As life stressors accumulate, people may find it more challenging to maintain the level of satisfaction first present at the start of the marriage.

Another point of interest relates to subjects' decreasing marital satisfaction scores as their numbers of children increase. Those subjects with no children reported higher marital satisfaction than subjects with one or more child. This can be explained in many ways: stress, for example. This study did not examine reasons for this result.

We are not likely to limit the number of years we stay married in order to decrease the mindlessness that we expect. As these data suggest, however, we may prosper from becoming more mindful to help keep our old relationships new.

\section{REFERENCES}

Bahr, S. J., Chappell, C. B., \& Leigh, G. K. (1983). Age at marriage, role enactment, role consensus, and marital satisfaction. Journal of Personality and Social Psychology, 43, 1088-1097.

Blum, J. S., \& Mehrabian, A. (1999). Personality and temperament correlates of marital satisfaction. Journal of Personality, 67, 93-125.

Bohlander, R. W. (1999). Differentiation of self, need fulfillment, and psychological well-being in married men. Psychological Reports, 84, 1274-1280.

Bouchard, G., Lussier, Y., \& Sabourin, S. (1999). Personality and marital adjustment: Utility of the five-factor model of personality. Journal of Marriage and the Family, 61, 651-660.

Bruch, M. A., \& Skovholt, T. (1985). Congruence of Holland personality type and marital satisfaction. Measurement and Evaluation in Counseling and Development, 18, 100-107.

Buss, D. M. (1991). Conflict in married couples: Personality predictors of anger and upset. Journal of Personality, 59, 663-688.

Buunk, B. P., \& Mutsaers, W. (1999). Equity perceptions and marital satisfaction in former and current marriage: A study among the remarried. Journal of Social and Personal Relationships, 16, 123-132.

Caspi, A., \& Herbener, E. S. (1990). Continuity and change: Assortative marriage and the consistency of personality in adulthood. Journal of Personality and Social Psychology, 58, $250-258$.

Fields, N. (1983). Satisfaction in long-term marriages. Social Work, $28,37-41$.

Gill, D. S., Christensen, A., \& Fincham, F. D. (1999). Predicting marital satisfaction from behavior: Do all roads really lead to Rome? Personal Relationships, 6, 369-387. 
Gottman, J. M. (1994). What predicts divorce? The relationship between marital processes and marital outcomes. Hillsdale, NJ: Lawrence Erlbaum Associates, Inc.

Gottman, J. M., \& Krokoff, L. J. (1989). Marital interaction and satisfaction: A longitudinal view. Journal of Consulting and Clinical Psychology, 57, 47-52.

Hjemboe, S., \& Butcher, J. N. (1991). Couples in marital distress: A study of personality factors as measured by the MMPI-2. Journal of Personality Assessment, 57, 216-237.

Holden, J. M. (1991). The most frequent personality priority pairings in marriage and marriage counseling. Individual Psychology, 47, 392-398.

Johnson, D. R., \& Booth, A. (1998). Marital quality: A product of the dyadic environment or individual factors? Social Forces, 76, 883-904.

Kaslow, R., \& Robinson, J. A. (1996). Long-term satisfying marriages: Perceptions of contributing factors. The American Journal of Family Therapy, 24, 153-170.

Kelly, E. L., \& Conley, J. J. (1987). Personality and compatibility: A prospective analysis of marital stability and marital satisfaction. Journal of Personality and Social Psychology, 52, 2740.

Kim, A., Martin, D., \& Martin M. (1989). Effects of personality on marital satisfaction: Identification of source traits and their role in marital stability. Family Therapy, 16, 243-248.

Kosek, R. B. (1996). The quest for a perfect spouse: Spousal ratings and marital satisfaction. Psychological Reports, 79, 731-735.

Langer, E. J. (1989). Mindfulness. Reading, MA: Addison-Wesley Publishing Company.

Langer, E. J. (1997). The Power of mindful learning. Reading, MA: Addison-Wesley Publishing Company.

Langer, E. J. (2001). Personal outlook scale. Manuscript submitted for publication.

Langer, E. J. (2002). Well-being: Mindfulness versus positive evaluation. In C. R. Snyder (Ed.), Handbook of positive psychology. Oxford University Press.

Lester, D., Haig, C., \& Monello, R. (1989). Spouses' personality and marital satisfaction. Personality and Individual Differences, 10, 253-254.
Lewak, R. W., Wakefield, J. A., Jr., \& Briggs, P. F. (1985). Intelligence and personality in mate choice and marital satisfaction. Personality and Individual Differences, 6, 471-477.

MacEwen, K., \& Barling, J. (1993). Type a behavior and marital satisfaction: Differential effects of achievement striving and impatience/irritability. Journal of Marriage and the Family, $55,1001-1010$

Mackey, R. A., Diemer, M. A., \& O’Brien, B. A. (2000). Conflict-management styles of spouses in lasting marriages. Psychotherapy, 37, 134-148.

Merves-Okin, L., Amidon, E., \& Bernt, F. (1991). Perceptions of intimacy in marriage: A study of married couples. The American Journal of Family Therapy, 19, 110-118.

Nemechek, S., \& Olson, K. R. (1996). Personality and marital adjustment. Psychological Reports, 78, 26.

Nemechek, S., \& Olson, K. R. (1999). Five-factor personality similarity and marital adjustment. Social Behavior and Personality, 27, 309-318.

Pasupathi, M., Carstensen, L. L., Levenson, R. W., \& Gottman, J. M. (1999). Responsive listening in long-married couples: A psycholinguistic perspective. Journal of Nonverbal Behavior, 23, 173-193.

Plechaty, M. (1987). Perceptual congruence of five attitudes among satisfied and unsatisfied couples. Psychological Reports, 61, 527-537.

Richard, L. S., Wakefield, J. A., Jr., \& Lewak, R. (1990). Similarity of personality variables as predictors of marital satisfaction: A Minnesota Multiphasic Personality Inventory (MMPI) item analysis. Personality and Individual Differences, 11, 39-43.

Sherman, R. G., \& Jones, J. H. (1994). Exchange on the MyersBriggs type indicator: A response to the article on "The validity of the Myers-Briggs type indicator for predicting expressed marital problems." Family Relations, 43, 94-95.

Winch, R. F., Ktsanes, T., \& Ktsanes, V. (1954). The theory of complementary needs in mate selection: An analytic and descriptive study. American Sociological Review, 19, 241-249.

Zimmerman, J. L., \& Dickerson, V. C. (1993). Separating couples from restraining patterns and the relationship discourse that supports them. Journal of Marital and Family Therapy, 19, 403-413. 